\title{
GALERI SENI INTERAKTIF
}

\author{
Bianca Marvella ${ }^{1)}$, Andi Surya Kurnia ${ }^{2)}$
}

1) Program Studi S1 Arsitektur, Fakultas Teknik Universitas Tarumanagara, marvellabianca@gmail.com 2)Program Studi S1 Arsitektur, Fakultas Teknik, Universitas Tarumanagara, andik@ft.untar.ac.id

\begin{abstract}
Abstrak
Generasi milenial merupakan generasi yang tumbuh di tengah perkembangan teknologi yang menjadikan mereka tech savvy (gemar teknologi). Pemakaian teknologi digital sudah sangat lekat dengan generasi milenial. Hal ini dibuktikannya dengan masuknya teknologi dalam aspek-aspek kehidupan, salah satunya adalah aspek sosial. Hari ini, dengan kecanggihan teknologi digital, sosial media menjadi sebuah perangkat interaksi yang dapat mengkoneksikan orang-orang tanpa batasan waktu dan tempat. Milenial, sebagai generasi pengguna teknologi digital terbanyak saat ini, mengekspresikan diri mereka dengan cara menunjukan momen, pengalaman, dan kesukaan, salah satunya lewat seni. Sebagai wujud ekspresi diri, seni tidak lagi terbatas pada koleksi patung, atau lukisan, tetapi lebih kepada momen-momen estetik yang dapat mereka bagikan di sosial media dalam bentuk foto maupun video. Di Indonesia sendiri, kebanyakan museum dan galeri seni hanya mewadahi ruang pamer yang terbatas pada objek-objek seni statis (tidak bergerak) padahal seharusnya mulai berkembang untuk mewadahi objek seni dinamis yang dapat berinteraksi langsung dengan pengunjung galeri. Oleh karena itu, dibutuhkannya sebuah ruang yang dapat mewadahi objek seni interaktif di era digital. Dengan menggunakan metode design research yang melakukan pendekatan terhadap ruang lewat observasi dan eksplorasi perilaku, Galeri Seni Interaktif dirancang dengan tujuan tidak hanya memberikan ruang ekspresi yang relevan untuk generasi milenial, tapi juga mendukung terjadinya interaksi langsung antar masyarakat sekitar melalui seni.
\end{abstract}

Kata Kunci: ekspresi diri; interaktif; seni; sosial media

\begin{abstract}
Millennials are the generation that lives among advance technology. The use of digital technology is inseparable from the millennial generation. This claim are proven by how technology sink in a lot aspects of life, social aspect as one of them. Today, with digital technology, social media becomes a tool to communicate that can connect people without the limitation of time and place. Millennials, as a generation who use digital technology the most today, open themselves up by showing moments, experiences, and pleasures through art. As a form of expressing oneself, art is no longer limited to a collection of sculptures, or painting, but rather to an aesthetic moments that they can share on social media in the form of photos or videos. In Indonesia, most museums and art galleries only accommodate exhibition spaces that are limited to static object (immovable), even though they are supposedly accommodate dynamic art objects that can be used interactively with visitor galleries. Therefore, a space that can accommodate interactive art objects in the digital age is needed. By using design research methods, carried out on space through observation and exploration, the Interactive Art Gallery not only provides relevant expression space for millennial generations, but also supports direct conversion between communities through art.
\end{abstract}

Keywords: art, interactive; self-expression; social media 


\section{PENDAHULUAN}

Perkembangan teknologi di era milenial menjadikan milenial sebagai generasi yang tech savvy (gemar teknologi). Hal ini mempengaruhi aspek sosial dari generasi milenial yang memicu terjadinya perubahan sosial, dari perilaku sampai interaksi. Hari ini, teknologi dapat ditemukan di segala penjuru dunia dengan keterjangkauan yang jauh lebih mudah dibandingkan masa sebelumnya. Tidak hanya oleh generasi milenial, tapi juga oleh generasi sebelumnya. Akibat dari kemajuan teknologi inilah yang membawa peradaban mengenal dunia digital lewat teknologi internet. Dari internet yang dapat mempertemukan pengguna dari segala penjuru dunia merubah cara perilaku manusia dari berbagai aspek kehidupan. Salah satunya adalah cara berinteraksi lewat dunia digital.

Kehadiran sosial media sebagai pusat informasi dan interaksi membentuk sebuah fenomena baru yaitu pencarian identitas diri. Sosial media memungkinkan adanya interaksi tanpa bertemu langsung dengan perjalanan informasi yang jauh lebih cepat. Perkembangan digital inilah yang memungkinkan pengguna hidup dalam dunia digital dan menjadi siapapun yang dia inginkan.

Instagram contohnya, merupakan salah satu media sosial yang paling marak digunakan orang saat ini sebagai sarana berinteraksi. Instagram sebagai perangkat interaksi, dibuat untuk mengkoneksikan orang-orang dengan cara berbagi moment dengan berfoto maupun video. Lewat dari sini, pengguna ingin menampilkan momen terbaik mereka untuk dibagikan ke teman-teman mereka. Namun kemudian, sarana berinteraksi ini mulai bergeser fungsinya. Tidak hanya sebagai sarana mengkoneksikan diri dengan orang lain tapi juga sebagai sarana untuk menunjukan identitas mereka.

Generasi milenial yang hidup di era digital inilah yang berdampak langsung terhadap krisis identitas lewat sosial media ini. Mereka mencari jati diri mereka, berlomba-lomba mencari identitas salah satunya lewat seni. Apresiasi generasi milenial terhadap seni kini hari kian meningkat berdasarkan pada kemunculan-kemunculan galeri, maupun museum yang semakin ramai didatangi dan tampil dalam sosial media. Tidak hanya itu saja, menurut Jakarta Open Data, pengunjung galeri dan museum kini kian meningkat dari tahun ke tahun. Seni yang dipakai untuk menampilkan identitas oleh generasi milenial tidak hanya berupa koleksi patung, atau lukisan yang dibagikan lewat sosial media, tapi mulai berkembang sebagai momenmomen atau pengalaman yang terdapat dalam galeri maupun museum. Dalam ruang seni tersebut, mereka tidak hanya mencari karya seni untuk diapresiasi, melainkan lebih kepada momen atau pengalaman estetik yang dapat mereka bagikan di sosial media lewat fotografi.

Melihat fenomena dari perubahan perilaku ini, arsitektur kini perlu menciptakan sebuah fungsi yang menawarkan pengalaman pengalaman untuk generasi milenial yang dapat dibagikan ke sosial media dalam bentuk video maupun fotografi sebagai wujud ekspresi diri.

\section{KAJIAN LITERATUR}

\section{Generasi Milenial dan Sosial Media}

Menurut William Strauss dan Neil Howe, Generasi milenial merupakan sekelompok orang yang lahir dari tahun 1981-1996. Menurut data dari Badan Statistik Indonesia (September 2017), generasi milenial menjadi penduduk terbanyak dalam usia produktif di Indonesia. Sebagai generasi yang hidup di tengah-tengah perkembangan teknologi, milenial memiliki karakteristik dan perilaku yang tidak sama dari generasi-generasi sebelumnya. Generasi milenial merupakan generasi yang tech savvy (gemar teknologi). 
Bagan 1. Grafik pemakaian internet berdasarkan generasi - Inggris

(\% penggunaan internet setiap harinya)

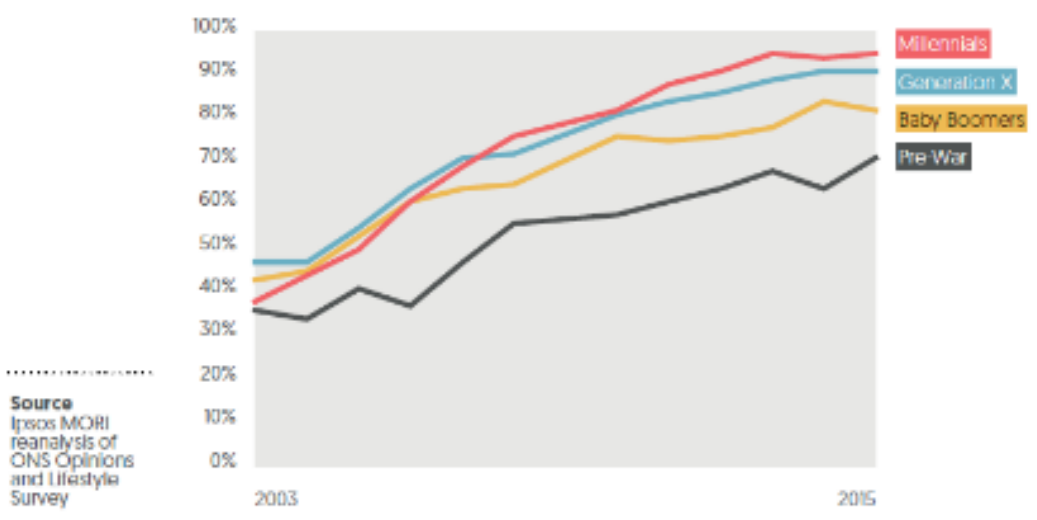

Sumber : IPSOS MORI 2016

Bagan 2. Grafik aktivitas penggunaan internet menurut tiap generasi

(\% aktivitas selama 3 bulan terakhir)

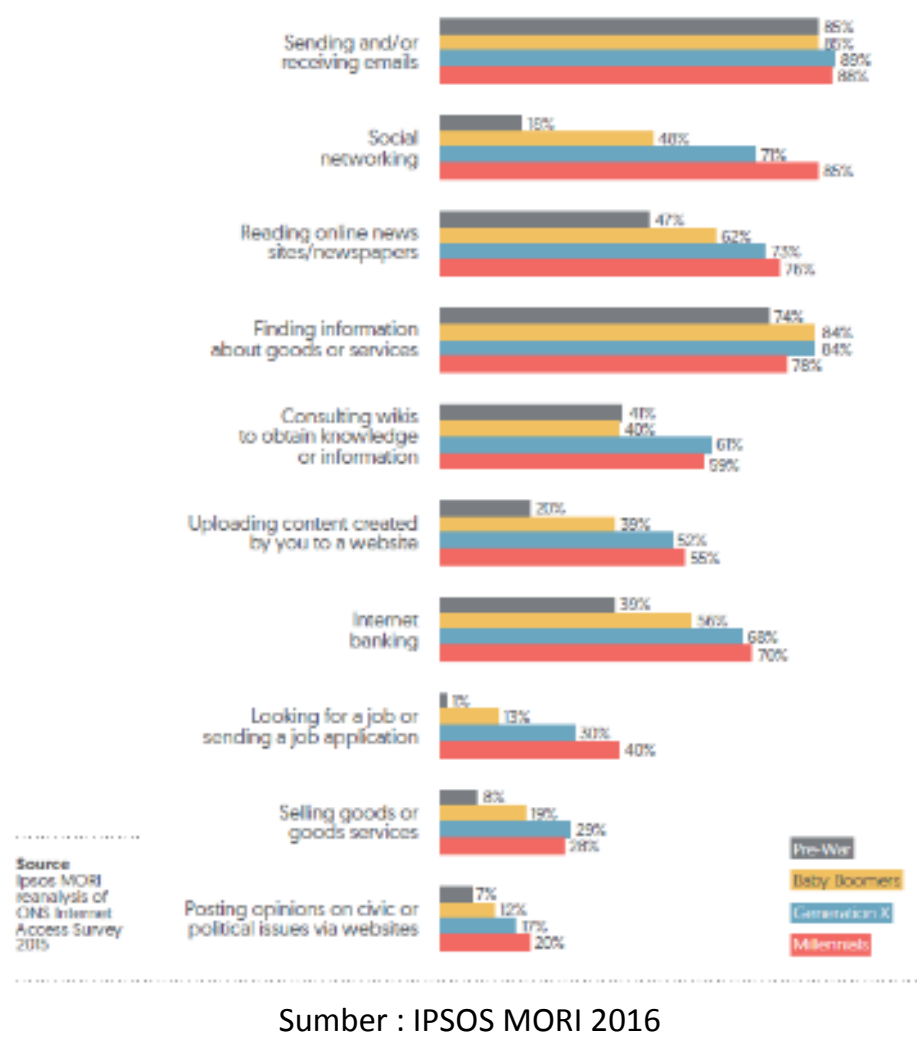

Sosial media menawarkan sesuatu yang baru yaitu sebuah pengalaman di mana semua orang bisa jadi siapa saja. Oleh karena itu, generasi milenial mengalami krisis identitas. Mereka mencari identitas karena teknologi menyamaratakan mereka (Michael Li 2018).

Orang mulai berlomba untuk menunjukan momen terbaik mereka. Memamerkan apa yang dapat mereka berikan dan menunjukan identitas mereka lewat apa yang mereka bagikan. Mengekspresikan diri atau memperlihatkan identitas, mereka tuangkan lewat postinganpostingan berupa foto keseharian, traveling, kesukaan termasuk seni. 
Seni

Seni didefinisikan sebagai sebuah ekspresi atau penerapan keterampilan dan imajinasi kreatif manusia, biasanya dalam bentuk visual seperti lukisan atau patung, menghasilkan karya yang dihargai terutama karena keindahan atau kekuatan emosional mereka. (Kamus Oxford).

Pada abad ke-20 seni didefinisikan sebagai sebuah konsep dan di abad ke-21, seni didefinisikan sebagai sebuah identitas (Beard E. 2018). Bagi generasi Milenial, seni merupakan sebuah cerminan idealisme dan aspirasi yang menunjukan siapa diri mereka. Berbeda dengan generasi baby boomers yang memakai seni sebagai aspirasi untuk membuat perubahan. Pergeseran makna seni ini menggeser pula sarana ruang untuk seni. Arsitektur yang mewadahi seni tidak terbatas sebagai ruang pamer untuk menjual karya seni, akan tetapi berubah menjadi ruang pamer untuk dibagikan sebagai wujud identitas seseorang lewat pengalaman.

Menurut Kennedy A. Seni bukan lagi sebuah objek, tapi sebuah pengalaman. Sifat generasi milenial yang kreatif, terus membawa perubahan dan membawa variabel baru dalam aspek seni. Kini milenial mencari tempat yang unik, menawarkan pengalaman lewat panca indra dan memiliki dampak emosional terhadap diri mereka.

\section{Seni Interaktif}

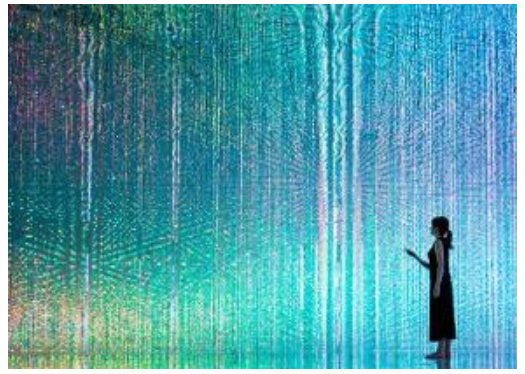

Gambar 1. Art Science Museum

Sumber : teamlab.art

Seni interaktif didefinisikan sebagai seni yang bergantung pada partisipan penikmat seni. Seni interaktif muncul pada akhir 1950-an karena keinginan seniman dengan keterbukaan seni. Seniman merancang instalasi yang bisa disentuh dan dimainkan. Kini, seni interaktif juga berbasis komputer dengan cara partisipan merespons teknologi yang dibuat oleh seniman. Perkembangan seni interaktif masih perlu dibeberkan secara menyeluruh, tetapi sejumlah penulis telah menuliskan dalam sejarah bagaimana kaitan digital, informasi dan seni yang lebih luas. Stephen Wilson dalam bukunya Information Art mengulas perkembangan seni menggunakan robot, gestur, sentuhan dll. (Wilson, 2002). Dalam publikasi selanjutnya, (Wilson, 2010) "Wolf Lieser" berbicara tentang seni digital yang mencakup bagian khusus mengenai objek dan seni interaktif di ruang publik (Lieser, 2009).

\section{Seni Digital}

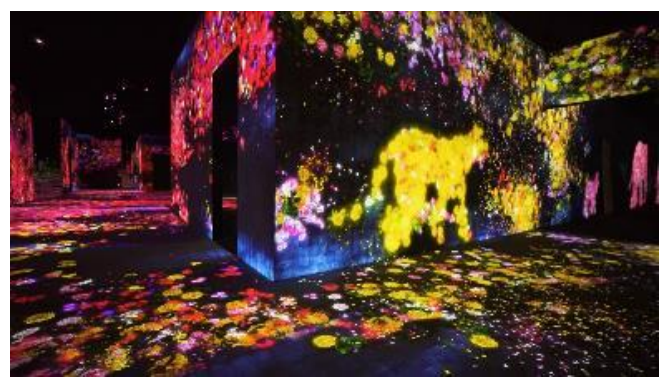

Gambar 2. Seni Digital menggunakan proyektor Sumber : teamlab.art 
Seni digital adalah sebuah karya yang dibuat dengan menggunakan teknologi digital atau yang ditampilkan dengan teknologi digital. animasi, rendering patung virtual 3D, serta proyekproyek yang digambungkan lewat teknologi merupakan bagian dari seni digital. Termasuk pembuatan gambar manual yang dilakukan di software seperti Adobe Illustrator.

Menurut Borko Furth, istilah seni digital merupakan istilah yang baru digunakan pada tahun 1970 an untuk mendefinisikan beberapa bentuk seni seperti seni multimedia (multimedia art), seni interaktif (interactive art), seni elektronik (electronic art) dan, seni media baru (new media arts).

\section{METODE}

Metode yang digunakan dalam mendesain proyek adalah metode design research. Metode design research adalah metode perancangan yang melakukan pendekatakan terhadap perilaku pengguna arsitektur. Metode ini dilakukan dengan cara melakukan observasi dan eksplorasi terhadap lokasi proyek dan perilaku dari pengguna sekitar, diutamakan generasi millennial. Hasil observasi lokasi tapak dan lingkungan serta perilaku pengguna (generasi milenial) menjadi hasil rujukan dalam merancang ruang arsitektur. Penggunaan metode ini tidak langsung mendapatkan sebuah bentuk arsitektur, tapi lebih kepada program dalam bangunan berikut dengan pengalaman pengguna dalam ruangan.

\section{DISKUSI DAN HASIL}

\section{Pemilihan tapak}

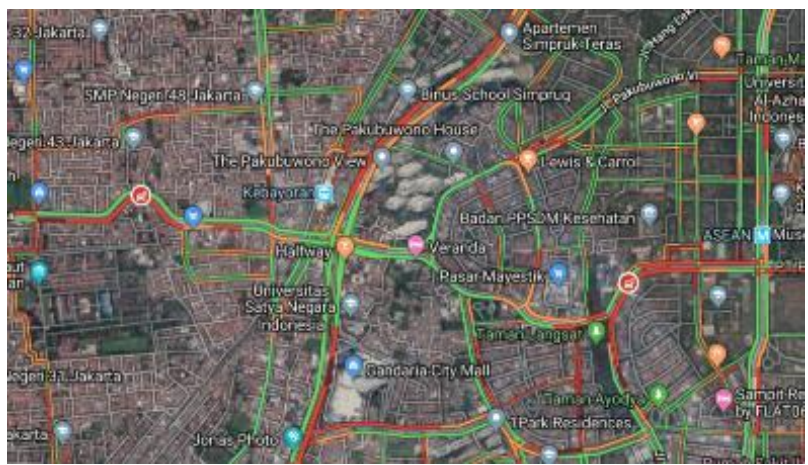

Gambar 3. Peta Kebayoran Lama dan sekitarnya. Sumber: Google Maps

Setelah melakukan penjabaran, proyek galeri seni interaktif membuat 3 kriteria utama dalam mencari tapak.

1. Lokasi dengan tingkat apresiasi terhadap seni.

2. Lokasi dengan tingkat ekonomi menengah ke atas.

3. Lokasi yang memiliki masyarakat berdigital.

Ketiga kriteria utama yang ditentukan membawa penulis pada lokasi tapak di Jakarta Selatan tepatnya di Kebayoran Lama.
Alamat
: Jl. Sultan Iskandar Muda, Kebayoran Lama, Jakarta Selatan
Luas Tapak $: 3.760 \mathrm{~m}^{2}$

Untuk kegiatan perkotaan seperti perkantoran, perdagangan dan jasa
1. $\mathrm{KB}: 4$
2. KDB : $50 \%$
3. $\mathrm{KLB}: 2$
4. $\mathrm{KDH}: 30 \%$
5. KTB : $55 \%$ 
Setelah melakukan survei lapangan, keberadaan tapak di Kawasan TOD (Stasiun Kebayoran lama dan halte Ps. Kebayoran Lama) membentuk perilaku commuting pada masyarakat sekitar.

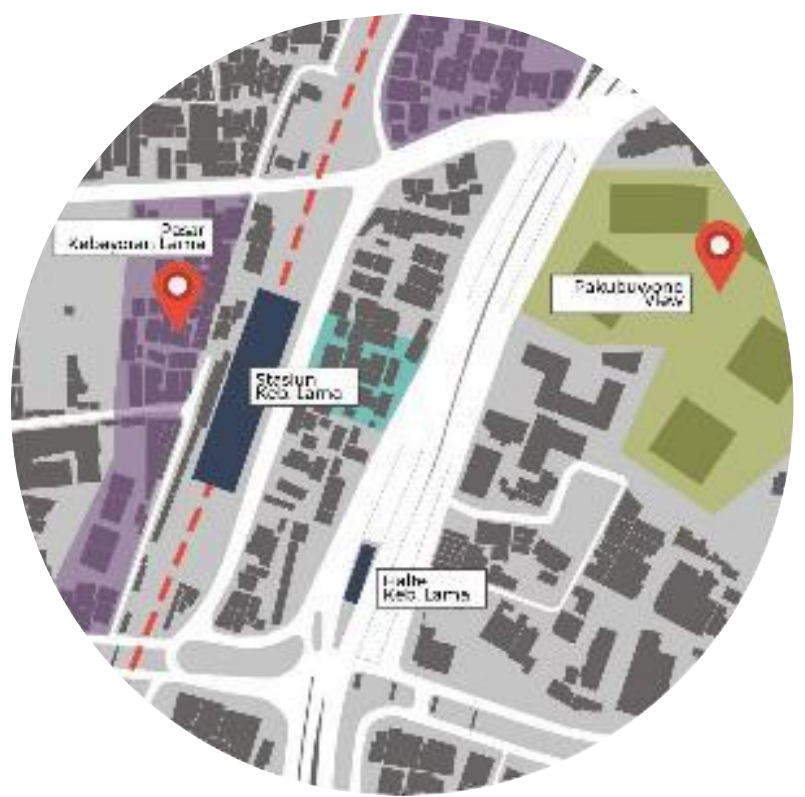

Gambar 4. Peta Lokasi Tapak dan Sekitarnya.

Sumber : Penulis, 2019

Selain itu, tapak eksisting memiliki keunikan tersendiri karena berada diantara kawasan elit dan kumuh. Dari sini, penulis melihat bahwa tapak proyek berpotensi menjadi proyek yang dapat menjembatani milenial menengah ke atas dan menengah ke bawah. Selain itu berada di lokasi TOD yang selalu dilewati masyarakat yang berkomuter membuat tapak ini menjadi lokasi yang dapat mempertemukan semuanya sebagai pusat interaksi.

\section{Analisis Program}

Berdasarkan penjabaran dari kajian teori yang telah dilakukan terbentuklah 3 program utama. Yang pertama adalah galeri, kedua adalah tempat pelatihan, dan ketiga adalah public space.

\section{Galeri}

Galeri sebagai program utama ditargetkan kepada milenial kelas menengah ke atas yang menikmati seni. Menyediakan ruang galeri seni interaktif termasuk seni digital.

a. Galeri tertutup

Galeri pertama merupakan galeri tertutup yang menyediakan wadah karya seni yang menggunakan elemen-elemen seperti air (hujan), pasir, tanah, dan lain-lain.

b. Ruang Interaktif

Ruang Interaktif merupakan tahap kedua dari eksplorasi pengunjung. Ruang interaktif menyediakan wadah untuk karya seni yang sifatnya aktif, bergerak dan memiliki interaksi langsung dengan pengunjung, misalnya disentuh, dilempar, atau dimainkan.

\section{c. Galeri Outdoor}

Galeri outdoor menyediakan karya seni yang membutuhkan ruang aktifitas yang lebih besar dan bebas gerak. Ruang galeri outdoor memiliki ruang teras untuk memamerkan karya yang digantung. Pada malam hari, pepohonan di sekitar galeri tersinar oleh lampu warna-warni sebagai wujud seni cahaya yang dapat dinikmati pengunjung. 


\section{d. Galeri Proyeksi}

Sebagai puncak eksplorasi, galeri proyeksi menyediakan tempat untuk karya seni proyeksi yang ditampilkan pada dinding, lantai, maupun langit-langit. Galeri proyeksi ini juga dapat menyediakan atraksi yang interaktif untuk pengunjung sebagai keseluruhan pengalaman seni.

e. Mural digital

Sebagai akhir dari eksplorasi galeri, mural digital menjadi ruang ekspresi diri dari pengunjung agar dapat menyampaikan pesan, kesan, atau gambar. Berbeda dengan dinding mural biasa, mural digital menggunakan teknologi sebagai media yang digunakan pengunjung lewat gadget mereka maupun gadget yang disediakan galeri. Pesan, kesan dan gambar yang mengunjung lukis di gadget yang disediakan dapat langsung muncul di proyeksi dinding mural. Gambar ini bisa bergerak dan berputar terus sehingga akan terus dapat terlihat oleh pengunjung yang lainnya.

2. Pelatihan

Pelatihan sebagai program kedua ditargetkan kepada milenial menengah kebawah sebagai terget utama, tetapi tidak menutup kemungkinan milenial kelas lain untuk bergabung. Program pelatihan ini menyediakan ruang untuk belajar lebih banyak mengenai seni, secara teoritis maupun digital, serta mendapatkan pelatihan yang berhubungan dengan seni seperti, kerajinan tangan, melukis, videografi, dokumenter dll.

\section{a. Main workshop}

Ruang workshop utama mewadahi aktivitas yang membutuhkan ruangan luas seperti melukis. Area workshop juga bisa dibuka ke arah ruang publik dan beralih fungsi menjadi area pasar seni.

b. Kelas Workshop

Berbeda dengan workshop utama yang menampung orang lebih banyak, kelas ini menampung orang dengan kapasitas lebih kecil. Area kelas ini memberikan pelatihan-pelatihan kecil berupa kursus videografi, handcraft dll. Yang dapat dilakukan dalam ruang yang lebih kecil.

\section{c. Collaborative space}

Collaborative space mewadahi aktivitas dengan sistem sewa perjam. Area collab ini tidak hanya dikhususkan untuk pekerjaan yang hanya menggunakan laptop maupun buku, tapi juga memperbolehkan aktivitas yang lebih seperti membuat prakarya, maket dll. Target pengguna dari collaborative space ini tidak hanya terbatas pada karyawan kantor, tapi juga kepada pelajar dan seniman.

\section{d. Studio sewa}

Berbeda dengan collaborative space yang hanya mewadahi aktifitas kecil, dan di sewa perjam, studio sewa menawarkan area untuk melakukan aktivitas yang sifatnya lebih besar. Studio sewa ini buka selama 24 jam dan ruangannya dapat digunakan untuk apapun, seperti kantor, studio rekaman, studio lukis, dll. Studio sewa di lantai 4 juga menyediakan fasilitas studio outdoor untuk mengguna yang memerlukan area outdoor seperti penggunaan cat pilox, palu, dll. Tidak hanya memberikan ruang-ruang kosong, studio sewa juga difasilitasi oleh kamar mandi dan loker yang dapat digunakan pengguna untuk mandi dan teras untuk beristirat dengan view ke arah ruang publik dan galeri seni.

\section{e. Gift shop}

Ruang souvenir disediakan untuk menjual karya-karya seni, pernak-pernik yang sudah dibuat dalam area workshop. Disini, selain memberikan sumbangsih hasil jual kepada masyarakat juga sebagai sarana yang memperkenalkan talenta seni seniman baru. 


\section{Ruang publik}

Ruang publik, menjadi program ketiga yang dibentuk sebagai pusat interaksi. Mempertemukan segala golongan masyarakat, penduduk maupun pengguna komuter. Ruang publik ini, sewaktu-waktu dapat menyediakan tempat untuk acara-acara terbuka yang mendukung bangunan seperti pasar seni.

\section{Konsep}

Interaksi menjadi sebuah konsep utama yang dinilai dapat menjembatani 2 kelompok masyarakat yang ada di sekitaran tapak. Masyarakat menengah ke atas (Pakubuwono, Simprug, Gandaria) dan masyarakat menengah ke bawah (Ps. Kebayoran Lama). Masyarakat menengah ke bawah merupakan sekelompok masyarakat yang masih perlu mencari nafkah demi memenuhi kebutuhan primer mereka. Berbeda dengan masyarakat menengah ke atas yang kini mulai memenuhi kebutuhan sekunder, atau bahkan tersier mereka yaitu, menikmati seni. Dari sinilah, untuk mengecilkan celah di antara mereka, dibentuklah sebuah interaksi. Masyarakat menengah ke bawah, khususnya milenial, dapat berinteraksi dengan masyarakat menengah ke atas dengan cara transaksi jual beli. Masyarakat menengah ke bawah menyediakan seni sebagai objek yang dinikmati masyarakat menengah ke atas. Selanjutnya, masyarakat menengah ke atas bisa juga berbagai pengetahuan dan keahlian kepada masyarakat menengah ke bawah sebagai wujud interaksi.

Tidak hanya menampung tempat bagi penduduk sekitar yang berbeda status sosial, proyek ini juga menampung tempat bagi mereka yang berkomuter ke ibukota melewati Stasiun Kebayoran dan Halte Ps. Kebayoran Lama. Dengan menyediakan tempat, proyek ini memberikan wadah yang mendorong terjadinya interaksi antar-masyarakat kota sekaligus menjadikan poin tambahan dalam meramaikan proyek.

\section{Bentuk Gubahan Massa}

Gubahan massa pertama-tama dibentuk lewat perilaku lingkungan sekitar yang menanggapi situasi.

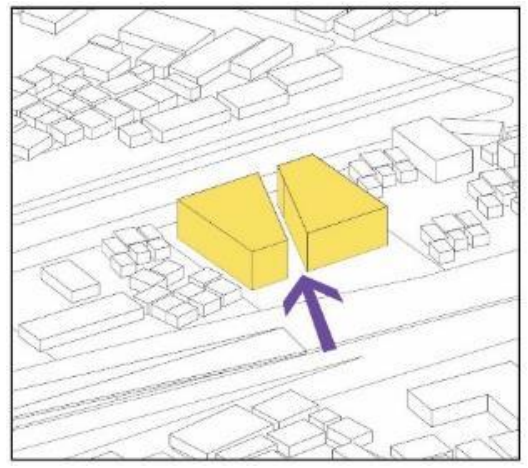

Gambar 5. Gubahan Massa

Sumber : Penulis, 2019

\section{Aksis pejalan kaki.}

Pertama-tama gubahan masa awal terbagi jadi 2 lewat sebuah aksis yang terbentuk dari perilaku pejalan kaki secara organik (lihat analisis tapak). Dengan membentuk sebuah jalan di tengah tapak, proyek memberikan kontribusi urban dengan menyediakan sarana pedestrian untuk pengguna sekitar lingkungan. 


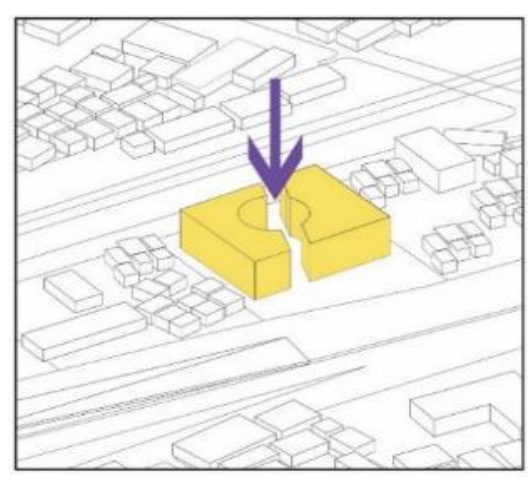

Gambar 6. Gubahan Massa

Sumber : Penulis, 2019

\section{Memusatkan}

Di tengah bangunan dibentuk sebuah void yang menjadi pusat interaksi bagi masyarakat sekitaran tapak. Dengan membentuk sebuah void yang dijadikan ruang publik, proyek memberikan kontribusi kepada kota untuk memberikan sarana ruang terbuka hijau dengan usaha untuk mengecilkan celah dua kelompok masyarakat yang ada pada kawasan Kebayoran Lama (lihat analisis tapak).

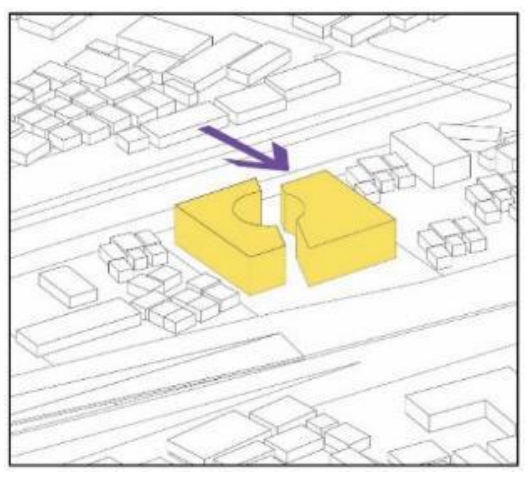

\section{Gambar 7. Gubahan Massa}

Sumber : Penulis, 2019

\section{Offset}

Gubahan massa kemudian di-setback bagian belakang dan depan untuk membentuk kedua entrance pada bangunan. Di bagian belakang di-setback ke dalam untuk merespon stasiun Kebayoran yang ada di belakang. Dan di depan dibentuk juga setback untuk membentuk entrance utama dari Jl. Iskandar Muda.

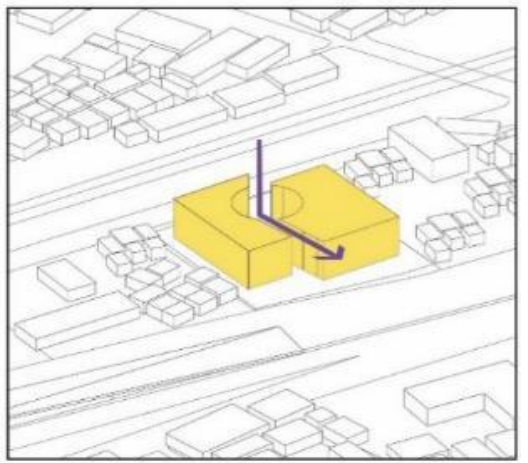

Gambar 8. Gubahan Massa

Sumber : Penulis, 2019 


\section{Membelokan Aksis}

Aksis yang sudah dibentuk di awal proses kemudian dibelokan untuk agar menciptakan gubahan masa yang membuat penasaran pengunjung. Selain itu, pembelokan aksis juga dilakukan agar ruang publik yang disediakan, tidak hanya dipakai secara cuma-cuma menjadi jalanan umum, akan tetapi tetap mendukung program utama dari bangunan yaitu galeri.

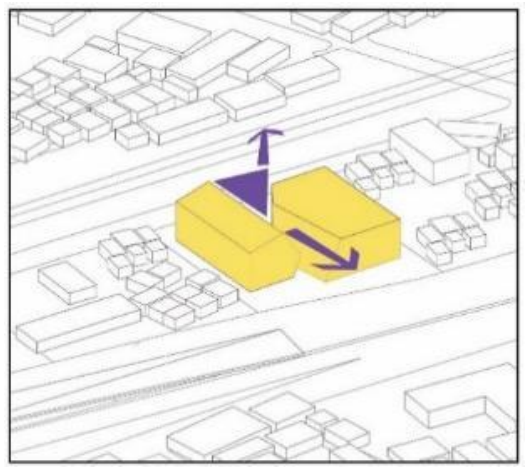

Gambar 9. Gubahan Massa Sumber : Penulis, 2019

\section{Penyesuaian}

Selanjutnya, gubahan massa yang terbentuk merupakan bentuk penyesuaian dari program dan respon dari sekitaran tapak yang membentuk bangunan.

\section{Keunggulan Desain}

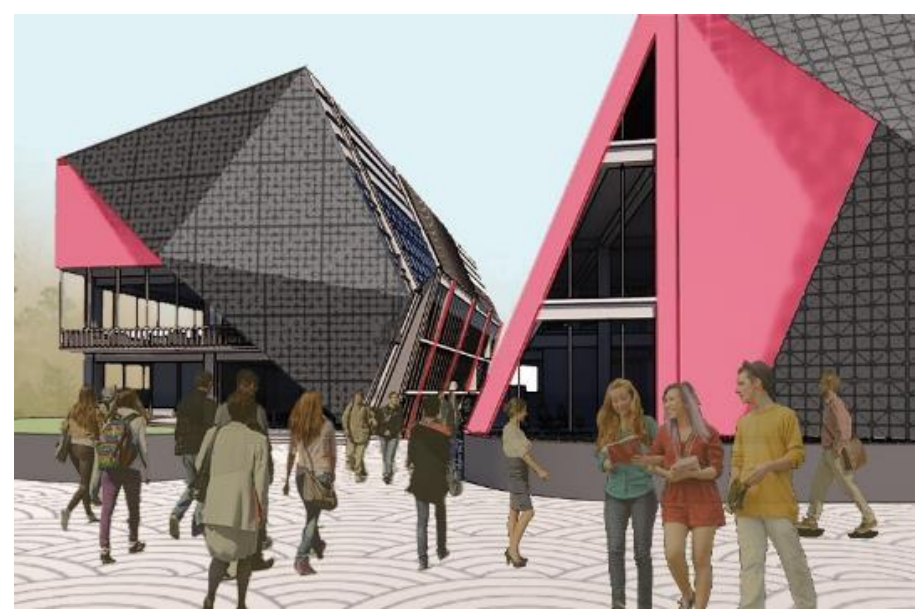

Gambar 10. Tampak Depan Bangunan

Sumber : Penulis, 2019

Proyek Galeri Seni Interaktif memiliki beberapa keunggulan desain dari tampilan bangunan yang dibuat eyecatching agar sesuai dengan fungsi bangunan sebagai galeri. Proyek bangunan menekankan desain pada pengalaman ruang yang memberikan pengalaman baru bagi pengunjung di era milenial. 


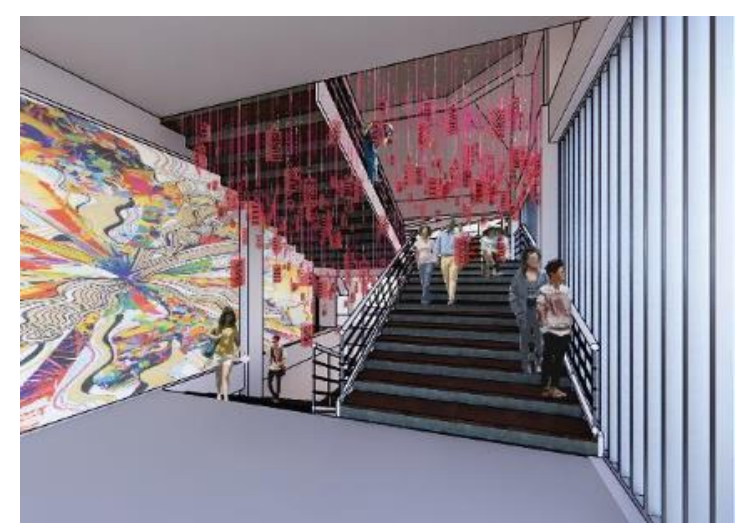

Gambar 11. Suasana Tangga Interaktif Sumber : Penulis, 2019

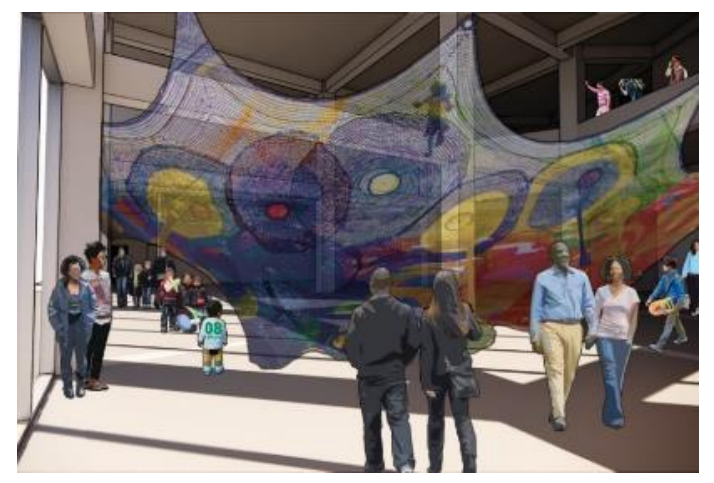

Gambar 12. Ruang Interaktif Sumber : Penulis, 2019

Outdoor deck yang menjadi keunggulan desain mewadahi ruang yang terbuka untuk umum. Ruang publik ini menyediakan jalan bagi perjalan kaki yang berkomuter menggunakan halte dan stasiun kebayoran. Dengan memberikan sarana pedestrian, diharapkan dapat ikut meramaikan seisi galeri beserta dengan workshopnya.

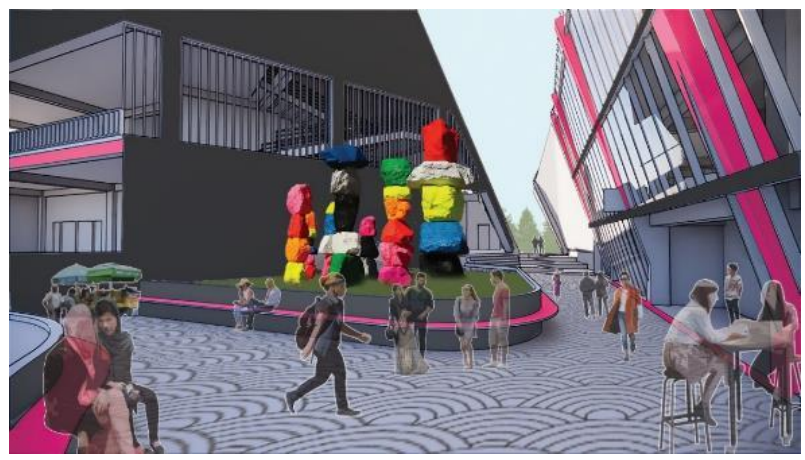

Gambar 13. Suasana Outdoor Deck

Sumber : Penulis, 2019

Selain itu, dengan memiliki sebuah kontur dan penataan ruang yang lebih beragam membuat ruang publik ini tidak hanya digunakan sekedar sebagai pedestrian, tapi dapat merangkul aktivitas lain seperti berkumpul, berjualan, dan tetap menarik pengunjung untuk masuk dalam bangunan sesuai dengan konsep dari proyek yaitu interaksi. 


\section{KESIMPULAN DAN SARAN}

Perancangan galeri seni Interaktif dilakukan dengan menggunakan metode perancangan design research yang mempelajari perilaku generasi milenial lewat observasi dan eksplorasi di lingkungan sekitar. Galeri seni interaktif menjawab kebutuhan generasi milenial dalam menghadapi fenomena sosial, identitas diri lewat sosial media. Proyek memberikan wadah bagi generasi milenial untuk menikmati momen-momen pengalaman ruang yang dapat mereka bagikan ke sosial media dalam bentuk video maupun fotografi sebagai wujud identitas diri.

Walau demikian, masih ada kekurangan dari perancangan proyek yang ada. Saran bagi pengembangan rancang kedepan adalah melakukan detail-detail arsitektur pada mekanikal elektrikal bangunan dan lebih fokus pada pendetailan pencahayaan dan pengudaraan yang dipakai dalam bangunan.

\section{REFERENSI}

Adweek. (2018, September 6). Influencing the Art Market: Milenial Collectors, Social Media and Ecommerce. Diambil kembali dari Adweek: https://www.adweek.com/digital/influencing-the-art-market-milenial-collectors-socialmedia-and-ecommerce/

Artwork Archive. (2017). The Art Market in a World of Milenials. Diambil kembali dari Artwork Archive: https://www.artworkarchive.com/blog/the-art-market-in-a-world-of-milenials

Dana, J. C. (1920). A plan for a new museum, the kind of museum it will profit a city to maintain. Woodstock, Vermont: ElmTree Press.

David A. Sturman, B. M. (2011). Changes in brain architecture, functional. The neurobiology of adolescence:

Dimock, M. (2019, Januari 17). Defining generations: Where Milenials end and Generation Z begins.

Furht, B. (2010). Handbook of multimedia for digital entertainments and art . Florida, USA: Springer.

Kennedy, A. (2018, August 3). HOW MILENIALS ARE CHANGING THE ART WORLD. Diambil kembali dari Artmarket: https://www.artmarket.guru/le-journal/market/milenialschanging-art-world/

Loria, K. (2018, April 19). Here's which generation you're part of based on your birth year and why those distinctions exist. Diambil kembali dari Bussiness Insider: Defining generations: Where Milenials end and Generation $Z$ begins

Pilkington, G. (2018, January 19). The Reason "Social Media" Will Soon Be An Art Form. Diambil kembali dari Mission.org: https://medium.com/the-mission/the-reason-social-media-willsoon-be-an-art-form-35742a32bcf2

Sutton, B. (2019, February 2). Museums Are Becoming More Diverse, But There's Still Work To Do. Diambil kembali dari Artsy: https://www.artsy.net/article/artsy-editorial-museumsdiverse-wor

Wilson, S. (2002). Information Art. Cambridge: The MIT Press. 